\title{
A nova "Era Dunga": o treinador como um dispositivo"
}

\author{
Gustavo da Silva Freitas ${ }^{1}$ \\ Luiz Carlos Rigo ${ }^{2}$ \\ Méri Rosane Santos da Silva ${ }^{1}$ \\ ${ }^{1}$ Curso de Licenciatura em Educação Física, Universidade Federal do Rio Grande, Brasil \\ ${ }^{2}$ Escola Superior de Educação Física, Departamento de Ginástica e Saúde, \\ Universidade Federal de Pelotas, Brasil
}

\begin{abstract}
Resumo: A Copa do Mundo é o evento futebolístico de maior protagonismo junto aos meios de comunicação. Neste sentido este artigo tem como objetivo central fazer uma análise sobre os discursos produzidos por uma parte da imprensa esportiva brasileira sobre a atuação de Dunga como treinador da Seleção Brasileira de Futebol. Fazendo uso da análise de discurso, no sentido que a utiliza Michel Foucault, analisou-se uma série de discursos publicados em diferentes veículos midiáticos (jornais, televisão, sites, revistas) no período compreendido entre os anos de 2006 ao início 2009. A conclusão do estudo mostra a existência de movimentos de resistência que a imprensa esportiva brasileira teve ao nome de Dunga. Destaca-se também o fato de Dunga representar outro perfil de técnico, referendando prioritariamente em seu capital de ex- jogador.
\end{abstract}

Palavras-Chave: Futebol; Seleção Brasileira; Treinador; Meios de Comunicação.

\section{New "Era Dunga": the coach as a dispositive}

Abstract: The World Cup is the football event of major position in the media vehicles. In this sense this article is mainly aimed to make an analysis of the speech produced by a part of the Brazilian sports press on the performance of Dunga as coach of Brazil National Football Team. Making use of analysis of discourse in the same way as Michel Foucault uses, we analysed a series of speeches published in different media vehicles (newspapers, television, websites, magazines) in the period between the years 2006 until the begging of 2009. The conclusion of the study shows the existence of resistance movements that the Brazilian sports media had with the name of Dunga. Also noteworthy is the fact that Dunga represent another profile of technician, endorsing priority in its capital of a former player.

Key-Words: Football; Brazil National Football Team; Coach; Media.

\section{Introdução}

A relação entre o torcedor brasileiro e a Seleção Brasileira de Futebol parece não obedecer a delimitações temporais ou espaciais, isto é, não se dá exclusivamente em períodos pré-fixados. É um arrolamento constante, de maior ou menor intensidade, mas que não cessa, não dá direito a intervalos. Por outro lado, não podemos negar que os momentos de maior intensidade, nos quais é observada toda uma movimentação social, comercial e midiática, assumem um "tempo em suspenso" (GUEDES, 1998) no instante de uma Copa do Mundo, quando o confronto estabelecido entre as nações supõe um sentimento de unidade.

Além disso, a memória de Copas do Mundo passadas vem à tona para se falar sobre a

\footnotetext{
1 Derivado da dissertação intitulada "Espírito de Seleção": um estudo dos discursos midiáticos a partir da Copa do Mundo de 2006, defendida em março de 2009 na Escola Superior de Educação Física da Universidade Federal de Pelotas (ESEF/UFPel).
}

próxima, constituindo-se em um fenômeno de caráter sociantropológico na sociedade contemporânea que, segundo GREGOLIN (2007, p. 16) tem a mídia como "principal dispositivo discursivo por meio do qual é construída uma 'história do presente' como um acontecimento que tenciona memória e esquecimento".

Sendo assim, as análises para a Copa do Mundo de 2010, disputada na África do Sul, tiveram respingos daquilo que aconteceu na Copa do Mundo de 2006, disputada em campos alemães. Em artigo recente ${ }^{2}$ (FREITAS; RIGO, 2009) foi apontado que a polifonia discursiva produzida a respeito do desempenho e do fracasso do selecionado brasileiro em 2006 tiveram por efeito, via produção midiática, a

\footnotetext{
${ }^{2}$ Artigo pertencente à dissertação de Mestrado da Escola Superior de Educação Física da Universidade Federal de Pelotas/RS - Brasil, a qual pretendeu analisar os discursos midiáticos produzidos em relação à Seleção Brasileira de Futebol durante a Copa do Mundo de 2006. O artigo referido está publicado na Revista Brasileira de Ciências do Esporte, vol. 30, Maio 2009.
} 
desconstrução de um modelo de Seleção Brasileira, desencadeando um processo de mudança no comando técnico, na busca por novos jogadores e na construção de outras identidades.

A transição de um momento que se mostrou insatisfatório na Copa do Mundo de 2006 para um período de renovação da Seleção Brasileira, passado o evento mundial, merece, assim, um olhar mais cuidadoso.

Parte desse projeto se deu na Copa América de 2007, tido pela crônica esportiva brasileira como um primeiro grande teste para o novo treinador, o ex-jogador Dunga. O final vitorioso para o Brasil nessa competição, no entanto, não assegurou a Dunga uma posição confortável frente ao torcedor, visto que parte da imprensa brasileira não aprovava o modelo em que os principais jogadores - leia-se Ronaldinho Gaúcho e Kaká - não haviam tido participação (ㅌEITAS; RIGO; PARDO, 2009).

Nessa linha, o objetivo principal deste artigo é analisar como a imprensa esportiva brasileira se postou perante a escolha de Dunga para o cargo de treinador, em substituição a Carlos Alberto Parreira, destacando 0 que enfatizaram os discursos sobre a Seleção Brasileira e o novo treinador, que circularam na imprensa esportiva entre os anos de 2006 a 2009.

\section{Caminhos Metodológicos}

Para realizar este estudo, utilizamos como suporte metodológico alguns elementos da Análise de Discurso na perspectiva de Michel Foucault, segundo o qual o discurso é compreendido como práticas que formam os objetos de que falam, sendo constituídas por determinadas condições de possibilidades, políticas e epistemológicas (FOUCAULT, 1995; 1998). Junto à Análise de Discurso, aproveitamos também alguns procedimentos e princípios metodológicos do Método Cartográfico, conforme Rolnik (2006), sobretudo a não obrigatoriedade de delimitar, a priori, as fontes que compõem o corpus da pesquisa, possibilitando cruzar e associar fontes de naturezas distintas. Isso porque a Cartografia permite inventar "outros caminhos nunca imaginados" (MAIRESSE, 2003, p. 262).

A seleção das fontes foi feita de forma assistemática, sendo utilizado como critério principal a referência direta e indireta ao nome do
Dunga no papel de técnico da Seleção Brasileira de Futebol. Essas referências foram garimpadas junto a diferentes veículos midiáticos (jornais, televisão, revistas, internet) no período compreendido entre a Copa do Mundo de 2006 até o fim de 2008. Esta variedade corresponde a: jornais brasileiros Folha de São Paulo/SP, Zero Hora/RS, Correio do Povo/RS, O Sul/RS e a revista Placar; programas esportivos de televisão na Rede Globo e SPORTV; e portais da internet com linhas esportivas como Globo.com, Terra e UOL.

\section{Scolari e Klinsmann: a referência que faltou em Carlos Alberto Parreira}

De todas as flutuações identitárias produzidas pela imprensa brasileira durante a Copa do Mundo da Alemanha, em 2006, uma das que mais chamou atenção foi a afinidade reivindicada por muitos discursos com a Seleção Portuguesa, principalmente após a desclassificação do Brasil, treinado por Carlos Alberto Parreira, frente à Seleção Francesa, como pode ser notado em publicações de periódicos do dia seguinte à derrota brasileira:

\section{Os Sem-Alma}

A alma que o Brasil não mostrou em Frankfurt estava em Gelsenkirchen, onde Portugal de Luiz Felipe Scolari, desfalcado de seu "Zidane" (o meia Deco ${ }^{3}$ ) matou-se em campo durante 120 minutos mais os pênaltis e foi à semifinal, igualando a façanha de 40 anos antes, quando tinha Eusébio, o Pelé luso. (FOLHA DE SÃO PAULO, 2006, p. D14)

\begin{abstract}
Matéria do caderno Correio da Copa do Jornal Correio do Povo/RS

França atropela sonho brasileiro: O gaúcho Felipão salvou o sábado dos conterrâneos que vestiram verde-amarelo em vão para torcer pela seleção brasileira. Enquanto os portugueses comemoravam a classificação para as semifinais da Copa do Mundo "com um toque de bola bem brasileiro", os torcedores brasileiros ficaram incrédulos diante da derrota de 1 a 0 para a França. (CORREIO DO POVO, 2006, p. 8).
\end{abstract}

Os "sem-alma" funcionou como uma reivindicação identitária, tendo a narrativa histórica como base. O discurso que eternizou a "alma do penta" na conquista da Copa de 2002, que presume uma série de significados - família,

\footnotetext{
${ }^{3}$ O brasileiro naturalizado português Deco é um entre tantos exemplos da proliferação que vem ocorrendo recentemente de jogadores brasileiros que se naturalizam em outros países. Esse crescente processo reconfigura os discursos identitários e os sentimentos de pertencimento que se estabelecem entre as seleções, os jogadores e os torcedores.
} 
raça, atitude, competitividade, eficiência -, foi evocado para notabilizar o que faltou em 2006, dessa vez sem Felipão no comando da Seleção Brasileira. O sobrenome que batizou um modelo de família para a Seleção durante um período recente e vitorioso se transformara num conceito torcido pelo brasileiro. $\mathrm{Na}$ medida em que a Seleção não vinha apresentando algo satisfatório, as lentes giravam gradativamente para Felipão, principalmente na comparação entre os estilos de comando dos treinadores das seleções brasileira e portuguesa e também pelos resultados alcançados por ambas. Em reportagem de página inteira do jornal Folha de São Paulo/SP, publicada na contracapa do dia 22 de junho de 2006 intitulada "Segredos de Família: enquanto Scolari se assume como 'paizão' do time português, Parreira minimiza o papel da harmonia com a equipe brasileira" -, já eram percebidos sinais de afinidade da imprensa nacional com o jeito Scolari de liderar:

[...] Scolari sempre se mantém na linha de frente das equipes que chefia. Busca carregar sobre seus ombros a responsabilidade mesmo quando está sob pressão. [...] E é assim agora, quando portugueses 0 indagam sobre a possibilidade de superar a melhor campanha do país [...] O discurso vai em direção oposta ao que Carlos Alberto Parreira fez ontem, na véspera do terceiro jogo do Brasil na Copa. Após duas atuações nas quais acabou questionado, o treinador minimizou sua influência. "Acho que decisivo sempre é o jogador. O técnico tem sua participação na formação da equipe, na filosofia de jogo, na mudança de ritmo, nas alterações feitas, mas o papel fundamental sempre será dos jogadores" [...] Ele diz não acreditar que a harmonia entre comandante e comandados seja decisiva. Um claro choque com o estilo do antecessor, que fez do estilo "paizão" um dos segredos para a conquista do penta. Em 2002, de tanto o gaúcho sair em defesa de seus jogadores e tomar atitudes para unir os atletas, o grupo ficou conhecido como "família Scolari". [...] Mais racional, Parreira em nada lembra o emotivo antecessor. (FOLHA DE SÃO PAULO, 2006, p. D12).

Recorrer ao nome de Felipão mexe com um imaginário social construído desde a conquista do pentacampeonato, o que pode ser tomado como uma estratégia do funcionamento discursivo midiático no estabelecimento de nova identidade, pois a:

[...] mídia produz sentido por meio de um insistente retorno de figuras, de sínteses narrativas, de representações que constituem o imaginário social. Fazendo circular essas figuras, ela constrói uma "história do presente", simulando acontecimentos em curso que vêm eivados de signos do passado. (GREGOLIN, 2003, p. 96).

O momento de desestabilização identitária, instalada em torno da Seleção Brasileira após a Copa do Mundo de 2006, propiciou a emergência de diferentes discursos articulados em relações de força, buscando dar explicações ao fracasso.

A individualização da culpa, que ora recaiu sobre alguns jogadores como Ronaldinho Gaúcho e Roberto Carlos ${ }^{4}$, estendeu os braços também para o técnico. Este foi identificado como um lugar passível de ser responsabilizado, partindo do princípio de que era ele quem deveria cultivar o sentimento de combatividade à equipe, conforme pode ser observado em matéria publicada na Revista Placar, em julho de 2006, pelo jornalista André Rizek:

Carlos Alberto Parreira. O principal culpado. Formou o grupo seguindo o clamor popular. Mas, passivo, sem vibração, em momento algum mostrou comando para transformar seu bando - de craques, é verdade - em um time de verdade, que honrasse a tradição vencedora da Seleção Brasileira. (REVISTA PLACAR, 2006, p. 46).

O cargo de treinador passa, então, a ter relevância na discussão como um dispositivo daquilo que se quer enquanto modelo de seleção de futebol. A centralização na figura do treinador, observada no discurso midiático, estava sujeita também à competência exercida por este em reunir um país em torno de um espírito de equipe, alimentando um sentimento de orgulho cívico, capaz de agrupar características mobilizadoras de identificação entre o torcedor e a Seleção.

Dessa forma, não só Felipão, mas também Jürgen Klinsmann - treinador alemão do selecionado do seu país - foi um exemplo de treinador que conseguiu corresponder a determinadas expectativas reivindicadas nos discursos produzidos pela imprensa brasileira. Klinsmann, com sua imagem de alguém que

\footnotetext{
4 A Revista Placar de julho de 2006, em reportagem de André Rizek, intitulada "O Fiasco tem Explicação?", tratou o desempenho da Seleção Brasileira de futebol na Copa do Mundo de 2006 como "crime de lesa-pátria", apontando os responsáveis por "arranhar a imagem do futebol brasileiro". Considerados pela matéria como culpados com dupla qualificação, estavam os jogadores Roberto Carlos e Ronaldinho Gaúcho. O primeiro, diz a matéria, "pela arrogância [...] No dia-a-dia de treinamentos, portou-se como se tivesse talento para resolver uma partida na hora em que desejasse [...]. Despede-se da Seleção como uma das imagens da derrota”. Já Ronaldinho Gaúcho foi considerado culpado "Por tudo o que não jogou [...]. Faltou ambição ao melhor do mundo [...] nunca assumiu a condição de cara que estava lá para decidir os jogos." (REVISTA PLACAR, 2006, p. 46).
} 
possui forte afinidade com 0 mundo dos jogadores aliada à sua preleção pela unidade nacional, é lembrado como um exemplo a ser seguido. A Revista Placar, de julho de 2006, comenta que Klinsmann conseguiu cativar o povo alemão ao levar "o desacreditado $22^{\circ}$ colocado do ranking da FIFA ao terceiro lugar na competição mais importante do futebol". (REVISTA PLACAR, 2006, p. 35).

A síntese entre Klinsmann e Felipão, pela forma de atuação de suas seleções, foi vista, principalmente pela imprensa brasileira, como um modelo de técnico que faltou à Seleção Brasileira. Curiosamente, a predileção da imprensa brasileira foi construída em torno de seleções que não foram as campeãs, mas que, segundo a fala midiática, demonstraram atitude de campeãs.

Eliminadas na semifinal respectivamente por França e Itália, Portugal e Alemanha fizeram uma disputa de terceiro lugar que foi explorada pela imprensa brasileira como um confronto entre duas seleções que honraram seus países, sobretudo pela conduta de seus treinadores. Klinsmann e Felipão eram pontos focais quando os jornais brasileiros comparavam os atributos que cada equipe dispunha para a decisão do terceiro lugar.

A postura de avaliar o desempenho de uma equipe de futebol a partir do seu técnico tornou-se recorrente no futebol moderno e goza de maior aceitabilidade ainda quando se trata de um fracasso futebolístico. Aliás, sobre isso, Wagg (2006, p. 3), ao falar sobre os treinadores de futebol, associando-os a políticas que o tornam celebridades, diz que:

A cultura futebolística criou o mito do treinador de futebol porque este serve os interesses de todas as partes envolvidas: administradores, proprietários dos clubes, meios de comunicação, ex-jogadores, jogadores e aspirantes a tecnocratas. E este paradigma é útil porque, em qualquer momento da vida de uma equipa importante, a explicação do desempenho dessa equipa pode ser reduzida a um único factor determinante: o trabalho do seu treinador.

Nesse sentido, um das primeiras medidas de impacto e repercussão midiática anunciada pela Confederação Brasileira de Futebol (CBF), após o fracasso da Seleção Brasileira na Copa de 2006, foi a escolha do substituto de Carlos Alberto Parreira.

\section{O dispositivo treinador}

Transcorrida a Copa do Mundo de 2006, algumas questões ficaram em aberto para a Seleção Brasileira de Futebol: quais são os caminhos a trilhar para que o torcedor brasileiro se sinta novamente identificado com sua seleção nacional de futebol? Como reconfigurar uma identidade fraturada, deslocada ${ }^{5}$ ? Mapeando parte da produção midiática em relação a essas questões, percebe-se que tão logo os jogadores se despediram da Alemanha, a imprensa já publicava, em pequenas notas, a primeira ação que ganhava, através da repetição, status de imposição: a mudança de treinador. As páginas dos periódicos do dia 3 de julho de 2006, dois dias após a eliminação, já divulgavam essa situação, como nos exemplos: "Nos bastidores, Luxemburgo é o nome da vez." (O SUL, 2006); e "Autuori é o preferido", "Wanderley Luxemburgo é o nome do secretário-geral da CBF". (ZERO HORA, 2006).

A não oficialização da demissão ou da renúncia ${ }^{6}$ de Carlos Alberto Parreira do cargo de treinador da Seleção Brasileira não impossibilitou que fossem criadas certas expectativas quanto ao nome de um novo comandante, que nesse caso representava outro perfil de técnico, sinalizando para uma renovação capaz de dar outras identidades ao futebol brasileiro e (re)conciliar o torcedor e sua Seleção. Em busca dessas outras identidades, ou ainda como forma de dar uma resposta aos reclames tão arraigados nos discursos midiáticos, menos de um mês após o final da Copa da Alemanha, o presidente da CBF, Ricardo Teixeira, anunciou o novo treinador, justificando: "A escolha do Dunga vai atingir em cheio o anseio dos torcedores brasileiros que querem na seleção um treinador vibrante" (GLOBO ESPORTE, 2006a).

Entre as inúmeras causas que se multiplicaram na imprensa tentando explicar o fracasso da Seleção em 2006, sobressaíram-se

\footnotetext{
${ }^{5}$ A Revista Placar estampou, na capa da edição de julho de 2006 uma foto do rosto de Luiz Felipe Scolari com a mão esquerda cerrada e erguida ao lado da manchete: "Por que precisamos dele. Felipão deu a Portugal o que faltou ao Brasil no Mundial. Será que Luxemburgo fará o mesmo na seleção?" (REVISTA PLACAR, 2006)

${ }^{6} \mathrm{Na}$ entrevista coletiva após a eliminação do Brasil na Copa da Alemanha, ao ser perguntado se continuaria ou renunciaria ao Brasil, à seleção, Parreira respondeu: "Não sei, veja bem. Eu não tenho essa preocupação se eu vou continuar, se eu não vou. É uma coisa que eu vou resolver, eu falei, depois da Copa quando chegar ao Brasil". (COPA DO MUNDO DE FUTEBOL, 2006). Na verdade, Parreira, já no Brasil, não chegou a pronunciar oficialmente sua decisão.
} 
as críticas que enfatizavam a falta de dedicação, de perseverança, de garra e de pegada, em sua maioria virtudes que ajudaram a consagrar Dunga como jogador e capitão da Seleção Brasileira de futebol. $O$ fato de Dunga, enquanto jogador, ter sido um símbolo emblemático dessas virtudes contribui para que ele fosse identificado como o técnico que poderia construir outro modelo, outro estilo - enfim, uma nova Seleção Brasileira de Futebol. Em outra matéria publicada pelo mesmo site momentos após o anúncio, lia-se a seguinte chamada: "Dunga, uma história de perseverança". E continuava: "Garra, determinação e vontade. Isso a torcida pode ter certeza que vai haver de sobra no comando da Seleção Brasileira." (GLOBO ESPORTE, 2006b).

Jorginho, ex-jogador da Seleção Brasileira que atuou durante a Copa do Mundo de 2006 como comentarista convidado pelo canal de televisão SPORTV, ao ser entrevistado pelo jornalista Thiago Dias sobre a indicação de Dunga, comentou: "[...] sei que muitos vão ter dúvidas sobre a capacidade dele, mas pelo que ele representa para o futebol brasileiro, foi uma escolha muito boa. O dia-a-dia vai ser importante para ele aprender tudo. O Dunga tem o perfil certo para esse processo de renovação" (GLOBO ESPORTE, 2006c).

Por não possuir um currículo como treinador, a avaliação voltou-se para o Dunga e suas passagens pela Seleção brasileira enquanto jogador, principalmente na Copa de 1990, marcada pela criação da imagem da Era Dunga como algo que deveria ser evitado, e a sua posterior redenção como capitão da Seleção que venceu a Copa de 1994. Aliás, a opção por um nome sem passado como treinador, com experiência apenas de ex-jogador, não foi uma aposta exclusiva brasileira. Na Copa do Mundo de 2006, por exemplo, houve os casos da Alemanha, com Jürgen Klinsmann, e da Holanda, com o exatacante Van Basten, e mais recentemente (2009) a argentina, com Diego Maradona. Assim, podemos estar presenciando a emergência de outro perfil de técnico para as seleções nacionais, referendado quase que exclusivamente pelo carisma e seu currículo de ex-jogador.

Apesar de muitos clubes já terem implementado a experiência do ex-jogador virar treinador, no caso da Seleção Brasileira o acontecimento movimentou os bastidores futebolísticos e se tornou o tema de debates entre treinadores e cronistas esportivos. Zico, por exemplo, argumentou que "é preciso ter experiência para saber como lidar com algumas situações". E acrescentou: “[...] isso não é novidade, o Falcão [treinador do Brasil no início dos anos 1990] também não tinha experiência. $O$ problema é para a pessoa, que sofre. Há diferença muito grande em conhecer o futebol e ser treinador". (FOLHA DE SÃO PAULO, 2007, p. D2).

Carlos Alberto Parreira adota a mesma linha de Zico e, em uma entrevista ao programa Esporte Espetacular da Rede Globo, no dia 13 de julho de 2008, comentou que "o caminho normal não é esse. [...] Então é uma mudança muito grande, não deveria ser a norma"7 .

A escolha de um nome com referencial de técnico zerado, após o fracasso na Copa, pode ser própria para um movimento de renovação. Por esse motivo, há que se pensar o nome de Dunga como um efeito retroativo de uma demanda discursivamente posta em operação durante e, sobretudo, após Copa de 2006, e não o contrário. Ou seja, não foi o nome de Dunga que acendeu uma nova perspectiva para o futebol brasileiro. Talvez a sua indicação represente a condensação de uma série de singularidades que, se dizia, estavam faltando ao futebol brasileiro e que apareceram com mais força, somente após o episódio da Copa de 2006. Nesse sentido, Dunga seria um agenciamento de algo que já estava em curso.

\section{Um projeto de renovação}

As mudanças previstas para a Seleção Brasileira passaram não só pela projeção do nome do treinador como também pelo projeto que se quis implementar. Ainda que todos vissem na figura de Dunga um estilo de vibração, de garra e de liderança, a partir de 2006 ficou em suspeição o modelo de Seleção Brasileira que se deveria buscar. Com o passar do tempo, isso ficou visível quando se observaram as alterações significativas na lista de atletas convocados para

\footnotetext{
7 Tostão, ex-jogador da Seleção na Copa de 1970 e atual cronista esportivo, foi um dos mais enfáticos a discordar da indicação do nome de Dunga. Em sua coluna na Folha de São Paulo, às vésperas da Copa América de 2007, ele escreveu: "Dunga e a CBF contribuem ainda mais para prolongar a decepção dos torcedores com a seleção. [...] Como alguém disse, Dunga comporta-se como um técnico da $C B F$, e não da seleção. Por essa postura servil, ele recebeu de retribuição, sem merecer, pois ninguém sabe se um técnico novato vai dar certo, o cargo de treinador do próximo
} 
os primeiros amistosos. Essa tendência foi explicitada pelo próprio presidente da CBF, Ricardo Teixeira, em muitas das suas entrevistas, como a que concedeu a Rodrigo Viga para o site Terra, afirmando que "[...] a perda da Copa da Alemanha fez com que a gente reestruturasse grande parte do nosso projeto de seleção brasileira, inúmeros astros não garantem o título mundial." (TERRA, 2006).

Com parte do diagnóstico na mão, Teixeira afirmava, a cada momento, o proveito do nome de Dunga, como mostra a matéria a seguir feita pelo jornalista Ricardo Gonzáles para o site Globo Esporte, publicada em 28 de dezembro de 2006:

Retrospectiva: A nova era Dunga na seleção

Técnico chega para resgatar o amor à camisa verde e amarela

Depois de um fracasso na Copa do Mundo, onde a marca que ficou foi a apatia de um time de craques que não precisavam lutar para serem titulares, o presidente da CBF, Ricardo Teixeira, tirou da cartola para substituir Carlos Alberto Parreira um conhecido motivador, que sempre esbanjou garra e dedicação à seleção brasileira, embora nunca tivesse sido técnico de futebol. (GLOBO ESPORTE, 2006e).

A renovação emergiu a partir da substituição de jogadores mais velhos, consagrados, por jovens talentosos, dispostos a lutar por um lugar na Seleção Brasileira ${ }^{8}$. E essa foi a tônica enfatizada pelo próprio Dunga em suas avaliações sobre a equipe, desde os primeiros amistosos sob seu comando. "O time foi bem. Mostrou determinação e no segundo tempo melhorou muito em relação ao primeiro. Os jogadores entenderam o que é ter o espírito da seleção brasileira". (GLOBO ESPORTE, 2006d).

As marcas da renovação fortaleceram-se a cada convocação, a cada competição. O discurso da renovação tornou-se a figura principal de trabalho do novo treinador, projetando-se como

Mundial, independentemente da qualidade do seu trabalho nesses três anos" (FOLHA DE SÃO PAULO, 2007, p. D5).

${ }^{8}$ Essa visão sobre o significado de renovar ganhou força na imprensa com o passar do tempo e dos jogos sob o comando de Dunga. Em um debate sobre o assunto, feito no programa Bem, Amigos, do canal SPORTV, no dia 12 de fevereiro de 2007, o comentarista Paulo Roberto Falcão e o repórter Mauro Naves tiveram a seguinte conversa: "Eu acho que aqui quando se fala em renovação, se fala em renovação do espírito, daquilo que se cobrou muito na Copa do Mundo daquela falta de atitude mais marcadora, mais agressiva, isso é o que se falou." (Falcão) [...] "Por isso até o Dunga foi o cara indicado para o momento: 'Pô, preciso de alguém com a força do Dunga, de chegar e chacoalhar o grupo'. Então, primeiro, eu acho que é um exagero a gente falar muito que tá renovando, tá renovando, não vai renovar tanto assim não." (Mauro Naves) um aliado para legitimar sua atuação, que continuava sendo alvo de severas críticas de boa parte da imprensa esportiva brasileira, mesmo após ter obtido resultados significativos, como a conquista da Copa América de 2007.

As declarações e os elogios de Dunga ao grupo que conquistou a Copa América provocaram uma nova onda de críticas de uma parte da imprensa esportiva do país. As opiniões negativas multiplicaram-se principalmente pelo fato de que reafirmar o grupo campeão daquela competição poderia significar deixar de fora da Seleção jogadores como Kaká e Ronaldinho Gaúcho, que haviam solicitado dispensa para não participar da Copa América. Assim, munida desse olhar avaliativo de plantão, parte da imprensa esportiva nacional logo fez questão de esquecer a Copa América e pautou os Jogos Olímpicos de Pequim de 2008 como mais um teste importante e necessário para avaliar o novo treinador.

Em terras chinesas, Dunga assumia abertamente sua ambição, dizendo que não haveria outro resultado satisfatório que não fosse o ouro olímpico e, para isso, evocava mais uma vez a atitude como uma das virtudes principais para vencer: "De acordo com o técnico, tão importante quanto a qualidade técnica, será ter uma postura vencedora em campo nas partidas da Olimpíada. 'Tem de ter atitude, isso é fundamental. Não vale participar da Olimpíada e não ganhar." (TERRA, 2008).

$\mathrm{Na}$ competição, o Brasil enfrentou a Seleção Argentina na semifinal. Ao contrário daquilo que Dunga esperava, a Seleção Brasileira não jogou bem e perdeu por 3 a 0 . Diferente do que fizera durante a Copa América, a imprensa esportiva se respaldou no resultado do jogo para fazer críticas à Seleção e a Dunga como treinador:

A seleção olímpica de futebol ainda vai disputar a medalha de bronze nos Jogos de Pequim, mas quem vai ter espírito olímpico para aplaudir uma nova vitória sobre a Bélgica? O Brasil perdeu ontem o seu Gre-Nal continental e isso ninguém perdoa. Mais do que perder, levou um banho de bola da Argentina e ainda apelou em determinados momentos, terminando 0 confronto com nove jogadores. Foi feio, muito feio. E ficou bem ruim a situação de Dunga. (ZERO HORA, 2008a, p. 46).

A derrota para a Argentina não teria que ser necessariamente vista como algo impossível de ocorrer, afinal tratava-se de um clássico entre as duas seleções de maior tradição no futebol sulamericano. Porém alguns acontecimentos são 
selecionados pelas mídias em função do potencial de saliência que reside ora no inesperado, ora na desordem, ora no notável (CHARAUDEAU, 2006). Nesse caso, a notabilidade que foi conferida à derrota deu a ela contornos vergonhosos e passou a ser tomada como matéria-prima para os discursos que reivindicavam a saída de Dunga. Exemplo disso está na coluna de Wianey Carlet, intitulada "Basta de Dunga e Ronaldinho", publicada no jornal Zero Hora/RS, no dia posterior à desclassificação na Olimpíada:

[...] O novo fracasso brasileiro só se justificará se a CBF assumir algumas providências inadiáveis. Dunga ainda não é treinador, poderá vir a sê-lo, mas ainda não é. Não é capaz de promover correções durante os jogos. Se a seleção tem problemas na etapa inicial, em qualquer jogo, é certo que os repetirá no segundo tempo. Intervalo de jogo, com Dunga, serve apenas como breve descanso e para um pouco de água gelada. [...] O Brasil dançou na Olimpíada, está em quinto lugar nas Eliminatórias e a única marca de Dunga, até agora, é o seu mau humor. Como está, não dá para continuar. (ZERO HORA, 2008a, p. 47).

Depois da desconfiança inicial, principalmente por sua inexperiência no cargo, a discussão quanto à capacidade de Dunga ser o técnico da Seleção Brasileira voltou à tona. Após os Jogos Olímpicos de Pequim, a maior parte da imprensa esportiva brasileira volta a enfatizar a falta de experiência e a incapacidade de Dunga para formar uma nova Seleção Brasileira vencedora. Essa linha de análise ganhou corpo e passou a circular em matérias publicadas em diferentes veículos da imprensa esportiva de todo o país, inclusive no Rio Grande do Sul, berço futebolístico de Dunga, como é o caso desta de Luiz Zini Pires publicada no Jornal Zero Hora/RS:

\section{Seleção Sem Suor}

Seleção é o sangue da Pátria. Seria a segunda pele natural do jogador de futebol. Não é mais, nem a quinta camada. Dunga cedeu um rio vermelho de suor ao tetracampeonato com suas chuteiras gastas de duas Copas. [...] Fora da Seleção, na Europa, onde fez carreira, Dunga sempre esteve longe das taças, dos títulos, das faixas. Ele pulou direto da confortável aposentadoria como jogador voluntarioso de futebol, nunca craque, para o posto mais cobiçado do país de 180 milhões de treinadores [...] Assumiu como o ex-atleta exemplar que faria a Seleção correr, suar como 11 craques famintos pela glória. Não deu garra ao time. Futebol que é bom também não. [...] Dunga não vai melhorar um milímetro, crescer um centímetro, Ihe falta base. [...] Se vale da vivência como jogador para treinar a Seleção. O que, claro, não basta. [...] Antes de assumir uma Seleção pentacampeã mundial, é necessário trabalhar numa categoria de base, num time médio, numa equipe de ponta, somar experiências, contar canecos de boa prata. Dunga foi um erro, uma experiência que não deu certo. (ZERO HORA, 2008b, p. 47).

A matéria revela uma inconformidade com aquilo que o cronista chamou de experiência malsucedida. Essa foi a linha de argumentação que prevaleceu na maioria das reportagens que se propuseram a avaliar $o$ trabalho $e$ a competência de Dunga. Ou seja, poucas foram as avaliações que tentaram fazer alguma análise isenta, utilizando-se de dados empíricos ou mesmo fazendo análises táticas, de conhecimentos técnicos, análise de esquemas e sistemas de jogo utilizados. Predominaram avaliações gerais, indo ao encontro ao que destaca Charaudeau (2006), quando assinala que as mídias preferem discursos mais genéricos, pois uma argumentação mais detalhada ou acadêmica atingiria um público muito reduzido.

Atentando para o fato de que a maior parte das avaliações da imprensa é feita a partir de elementos do cotidiano futebolístico aliados a fatores de cunho comportamental e emocional, sem maior atenção para 0 conhecimento especifico do futebol, caberia perguntar se a escolha de um ex-jogador para a função de treinador da Seleção Brasileira não estaria também almejando atender a essa demanda produzida pelas mídias. Estaríamos presenciando a emergência de outro perfil de treinador para a Seleção Brasileira? Talvez um perfil particular, propício para um momento de renovação, no qual o fato de ser um ex-jogador de Seleção, com respeito entre os jogadores e carisma com a torcida seja tão ou mais relevante quanto o conhecimento técnico e tático do futebol.

O mais curioso de tudo isso é que, mesmo enquanto jogador, Dunga nunca foi um consenso dentro da imprensa futebolística brasileira. Por não ser um atleta extremamente habilidoso, ele não costumava ser lembrado como alguém que melhor representasse as singularidades do futebol brasileiro.

$O$ fato de ser questionado, de não ser um consenso para a maioria da imprensa esportiva do país, antes como um grande jogador e agora como técnico, é mais um indicio de que Dunga representa outra era, uma nova cultura para o futebol brasileiro.

A imprensa esportiva, via de regra, sonha, reclama e reivindica uma Seleção Brasileira que 
sempre vença seus adversários, por goleada e dando espetáculo. Diferente disso, Dunga representou como jogador - e parece que também o fez como treinador - um futebol que se distancia dos discursos duais e essencialistas que tentam dividir o futebol em Futebol-Força versus Futebol-Arte, Escola Brasileira (ou Sul-Americana) versus Escola Europeia. Ao contrário disso, Dunga representa o futebol híbrido, que não opõe e nem separa o condicionamento físico da habilidade técnica. Oriundo dos processos migratórios e de circulação $^{9}$ de jogadores e técnicos, esse futebol é o resultado de uma fusão entre o futebol europeu e o sul-americano.

A mercantilização do futebol, que tem por um de seus efeitos a saída e a circulação de jogadores brasileiros pelas mais variadas equipes e campeonatos do mundo, vem borrar aquilo que se pode chamar de futebol brasileiro ( $\underline{\text { ALVITO}}$, 2006). As atuais configurações futebolísticas internacionais exemplificadas acima mostram os riscos presentes nos discursos identitários que ficam à caça de uma única e verdadeira identidade para o futebol brasileiro.

Porém, segundo MacNeill (2006), a identidade não é um conceito obsoleto, mas que necessita de uma reteorização, devendo-se, principalmente, considerá-la um processo. Ela afirma que a identidade é um discurso dominante na cobertura midiática, principalmente em eventos esportivos, porque esses, quando em nível internacional, organizam-se principalmente a partir da noção de Estado-Nação e também "porque são frequentemente utilizados por grupos nacionais de telecomunicações para angariar audiências maiores para toda rede: as dimensões culturais, políticas e econômicas estão realmente interligadas." (ibidem, p. 15).

Constituída por relações de poder, a identidade alcança o status de instabilidade, inconsistência, um ato performativo que está ligado a estruturas discursivas (SILVA, 2000). A partir disso, a multiplicidade e a dispersão dos discursos produzidos pelas mídias, ao tempo em que se diferenciam naquilo que enunciam, possuem em comum a referência pelo uso da

\footnotetext{
${ }^{9}$ Sobre os efeitos da circularidade dos jogadores de futebol na caracterização cultural das práticas futebolísticas dos países, ver a conclusão do estudo de Luiz Carlos Rigo (2004). Apoiado nos escritos de Michel Serres, Rigo aponta um estado mestiço do futebol para o século XXI com o rápido cruzamento e mistura das diferentes culturas do futebol, proporcionado pelo afrouxamento das fronteiras entre países e continentes.
}

identidade, se não diretamente, em formas alusivas a ela. Nesse jogo, um dos movimentos diretos que se faz é associar à Seleção Brasileira o nome do seu treinador, ou seja, é a Seleção Brasileira do Dunga ou, abreviadamente, a Seleção do Dunga, assim como já foi a Seleção do Parreira, a Seleção do Felipão, entre tantos. Dessa forma, a imprensa cola o perfil da Seleção Brasileira à "cara" do técnico, ainda que, ao mesmo tempo, cobre que este tenha um compromisso em colocar em prática um provável estilo de jogo que tenha a "cara" do futebol brasileiro.

No caso de Dunga, por aquilo que aparece no campo midiático, essas "caras" em parte são dissonantes porque 0 ex-jogador e agora treinador nunca foi representativo do futebol brasileiro enquanto talento técnico. Por outro lado, encarna outras virtudes como força, garra e vibração, que serviram de matéria-prima para que seu nome fosse lembrado como uma referência do futebol brasileiro, capaz de assumir o cargo de técnico da Seleção em um momento de crise, pós-Copa do Mundo de 2006, na perspectiva de mudar, renovar e construir novos caminhos para a Seleção.

A ideia de superação - como a de que vácuos de talento devem ser compensados pelo esforço individual e coletivo, por exemplo -, tão necessária para a Seleção Brasileira depois da Copa do Mundo da Alemanha, foi lembrada pelas mídias quando ressaltaram as primeiras conquistas de Dunga ${ }^{10}$ na condição de técnico. Esse processo de mitificação, na perspectiva de Eco (1979), é entendido como:

[...] simbolização incônscia, identificação do objeto com uma soma de finalidades nem sempre racionalizáveis, projeção na imagem de

10 O colunista Mário Marcos de Souza, do jornal Zero Hora/RS, publicou uma coluna dois dias depois da conquista do título da Copa América 2007, na qual enfatizou as provações de Dunga. O título "O hábito de vencer barreiras" já expressa a árdua, porém usual, tarefa de ser bem-sucedido nas lutas enfrentadas. Segue a coluna: "Ao longo de uma carreira iniciada nas categorias de base do Inter, o gaúcho Dunga habituou-se a superar desafios e, principalmente, a vencer preconceitos. Ficou duramente marcado em 1990 ao ter seu nome associado a um período ruim do futebol brasileiro, mas quatro anos depois não apenas venceu as desconfianças como virou um dos responsáveis pela conquista do Tetra. Romário, eleito melhor jogador daquela Copa, já disse: sem Dunga e sua liderança, o título talvez não tivesse chegado. Nem assim Dunga virou unanimidade até porque, na análise da campanha, seu papel - valorizado por Romário - sempre foi subestimado. Agora, de novo superando as previsões, ele volta vitorioso da Venezuela. Como antes, continua sendo olhado com alguma má vontade por muitos, mas nada parece capaz de alterar seu estilo. É um fenômeno de resistência." (ZERO HORA, 2007a, p. 49). 
tendências, aspirações e temores particularmente emergentes num indivíduo, numa comunidade, em toda uma época histórica. (p. 239).

Nesse sentido, Dunga passa a ser extraordinário, um mito, mais pela projeção da forma como enfrentou as dificuldades na sua carreira do que, para muitos, pela capacidade técnica de representar o futebol brasileiro. Sua mitificação está baseada em termos de esforço e sacrifício, condições essenciais, segundo Helal (2001, p. 144), para um mito ser firmado como tal:

[...] não basta o ato heroico em si, de forma isolada - no caso, as vitórias, as realizações e os gols no futebol. O herói tem que preencher outros requisitos - tais como perseverança, determinação, luta, honestidade, altruísmo para se firmar no posto.

Para além dessa dimensão, lembra Eco (1979) que esse reconhecimento emblemático do mito é contrabalançado com a imprevisibilidade das histórias que estão sendo contadas durante o próprio tempo em que acontecem. Ou seja, o modelo que Dunga representa tem de ser submetido a constantes provações que possibilitem reatualizar seu status de mito. E, para enfrentar essas provações, apela-se para a humanização do mito, ou seja, diz-se que o personagem assume uma "personalidade estética"11, sendo comparável, a partir disso, a qualquer mortal ${ }^{12}$. O mito deve agir, portanto, com base em comportamentos tidos como naturais, ainda que seja capaz de feitos sobrenaturais, pois ele funciona sob a condição de estar inserido nas coisas do presente, "ligado à existência do mundo humano e cotidiano da temporalidade" (ECO, 1979, p. 253).

\footnotetext{
11 Termo utilizado por Eco (1979) para definir a coparticipação de comportamentos e sentimentos comuns a qualquer humano que não assumem a universalidade do mito, apesar de fazer parte dele.

${ }^{12}$ No dia em que a seleção brasileira jogaria sua primeira partida válida pelas eliminatórias para a Copa do Mundo de 2010, Zero Hora/RS publicou uma reportagem feita pelo jornalista Diogo Olivier na capa da seção de esportes, intitulada "O Jardineiro Fiel", mostrando justamente esta junção entre o homem e o mito Dunga: "Está nas mãos de um jardineiro o sonho do Hexa - que começa neste domingo, em Bogotá, contra a Colômbia. Como não se tem notícia de jardineiros indisciplinados e Dunga assumiu a Seleção Brasileira justamente para acabar com a desordem no vestiário, trata-se de uma descoberta promissora. Os vizinhos do técnico são capazes de descrever com riqueza de detalhes a cena a seguir: Dunga cortando a grama, varrendo a calçada de bermudas e chinelos, regando as flores, ajeitando os enfeites. [...] Não deve ser nada fácil cuidar de tudo. É um jardim complexo. Como é complexo o vestiário da Seleção, cuja ausência de comando resulta em times sem alma, como o da Copa do Mundo de 2006. Além do mais, o capitão do Tetra é um jardineiro fiel. Trabalha todos os dias." (ZERO HORA, 2007b, p. 47).
}

Contudo a maneira como responderia ao desafio de renovação e (re)construção da Seleção Brasileira colocado à sua frente ainda era desconhecido, em parte, tendo um enredo inacabado. Aliás, nem Dunga, o próprio personagem do mito, é dono de sua história, pois em primeiro plano está a invenção de um enredo contado por mil discursos, neste caso, os discursos midiáticos.

Ao final de 2008, esse enredo ganhou outro capítulo interessante com a apresentação de Maradona como titular do cargo de treinador da Seleção Argentina. Essa atitude efervesceu o cenário futebolístico sul-americano, com destaque para a imprensa brasileira, que resolveu tecer comparações com o técnico da "casa". Dentre as similaridades abordadas na avaliação de ambos, chama atenção a que discursa sobre a falta de experiência na função. Entre discursos favoráveis e contrários $^{13}$ em relação a essa questão, a escolha de Maradona, assim como a de Dunga, suscita a emergência de outro paradigma para o perfil de treinador de seleções nacionais, justificado, principalmente, pelo capital acumulado no mundo da bola enquanto ex-jogadores. Além disso, é possível seguir com as análises comparativas pelo lado mitológico encontrado nos dois personagens, pela rivalidade entre Brasil e Argentina e pela atualidade do acontecimento.

\section{Conclusões}

É no sentido apontado acima que Dunga, como mito, pode ser consumido, numa produção midiática das histórias, das lutas e dos dramas pelos quais passa. Dentro desse consumo, convocado a empreender um "espírito de Seleção" reivindicado à Seleção Brasileira de futebol após a Copa do Mundo de 2006, o nome

\footnotetext{
13 Coluna de Paulo Roberto Falcão em Zero Hora/RS, um dia após o anúncio de Maradona pela Associação de Futebol da Argentina (AFA): "A confirmação de Diego Maradona como técnico da Seleção Argentina está provocando uma grande polêmica no mundo do futebol [...]. Não tem experiência como técnico, é verdade. Mas quem disse que inexperiência é indicativo de fracasso? Ou que experiência é determinante de sucesso?" (ZERO HORA, 2008c, p. 58). Em direção inversa, mas no mesmo jornal e no dia seguinte, o colunista Wianey Carlet, sob o título "Dunga e Maradona, os mesmos erros", opina: "Eu já me preparava para reprovar a decisão da Associação de Futebol Argentina, que contratou Maradona para ser o treinador da principal seleção do país, quando lembrei que teria a obrigação de repetir as mesmas críticas para a CBF por ter escolhido Dunga para dirigir a nossa seleção. [...] O problema é que seleções importantes como a brasileira e a argentina precisam muito mais do que bom comportamento dos seus treinadores. Experiência é essencial para que um treinador possa bem dirigir um grande selecionado. E, neste quesito, Dunga e Maradona seriam, amplamente, reprovados." (ZERO HORA, 2008d, p. 53).
} 
de Dunga, como expoente de liderança desse trabalho, provoca uma reflexão acerca do significado de "espírito de Seleção", que, num primeiro momento, parece ser um conceito em aberto.

Como vimos, a figura do mito é construída sob a marca do espírito guerreiro, de luta, de obstinação, e que, com isso, vence. Seria esse o espírito de Seleção discursado pelo campo midiático como o desejo de consumo do torcedor brasileiro? A resposta é positiva desde que os discursos destacados se refiram mais a esses traços do que àqueles referentes à habilidade técnica do jogador brasileiro. Nessa linha, a participação brasileira em campeonatos mundiais, de 1994 para cá, indica essa tendência, sobretudo pela regularidade discursiva de elementos como raça, empenho e doação no campo de jogo, seja nas conquistas - como nos casos do tetracampeonato em 1994 e no penta em 2002 -, seja aparecendo como falta - como visto na campanha fracassada de 2006 na Alemanha.

Em contrapartida, há outras formações discursivas que aparecem no campo da produção midiática e que tentam negar um vínculo com um futebol (des)qualificado por alguns, dito operário, como se fosse algo menor, impróprio para a tradição do "país do futebol". Afinal, o operário estaria ligado a concepções que denotam esforço, garra e sacrifício, pois é aquele que labuta desde cedo, que utiliza da sua força para produzir, que se dedica para cumprir as tarefas diárias, que precisa de disciplina no ambiente de trabalho, características que não se aplicariam a um ideal de futebol à brasileira. Um "espírito de seleção" brasileira, para esses outros discursos, combinaria com um estilo mais plástico, artístico, gingado, envolvente de jogar, comprometido com a habilidade do jogador brasileiro.

Esse campo de lutas discursivas que pleiteiam a legitimidade desse "espírito de Seleção" faz das identidades um eterno mutante que, por definição de Laclau (2005), são significados que flutuam entre discursos opositores e de situação. Objeto de disputa, seu sentido permanece num constante estado de suspensão, indeciso entre as fronteiras equivalenciais de um lado e outro, nas quais não se articulam outra coisa senão as diferenças. Isso porque, ao mesmo tempo em que um discurso identitário se afirma pela condição que o diferencia do outro, está afirmando também o discurso identitário do outro.
Para além disso, uma identidade é formada a partir daquilo que a rechaça, não como simples diferença que designa sempre o outro, mas como algo que renegocia - não como aliança, mas como luta - as formas de sua presença. A identidade, portanto, é processada dentro desse sistema de poder, de relações de poder, presentes no campo midiático, que impedem sua total constituição, e, ao mesmo tempo, são a sua condição de existência.

Temos aí discursos particulares que são produzidos para dar sentido ao universal, que nunca chega a ser preenchido. Discursos dedicados a arrastarem seus particularismos a uma função universal, mas só conseguem isso de modo temporário e contingente, dependente de uma competência política para tal (LACLAU, 1996).

Se, em alguns momentos, a presença de Dunga fez com que o "espírito de Seleção" fosse sinônimo de valentia, de garra, de raça, de amor à camisa verde-amarela, esse discurso sempre conviveu com a iminência de sua destruição em prol dos discursos que apostavam que a Seleção não iria vencer a Copa do Mundo, único resultado que historicamente tem se mostrado convincente à maioria dos brasileiros e também da imprensa esportiva do país.

Como o hexacampeonato não aconteceu, após a Copa predominou entre os brasileiros e na impressa esportiva a avaliação de que, na nova Era Dunga, o treinador fracassou. A derrota de virada para a Seleção Holandesa por 2 a 1 e a consequente desclassificação ajudaram a legitimar os discursos que insistiam na fragilidade da "Seleção de Dunga".

Entre os muitos acontecimentos referentes à Seleção Brasileira na Copa de 2010, destacou-se - tumultuado relacionamento que Dunga estabeleceu com boa parte da imprensa esportiva brasileira durante seu período no comando da Seleção e que chegou ao ápice de desentendimento durante a competição na África do $\mathrm{Sul}^{14}$. O quanto o relacionamento do treinador com a imprensa influenciou o estado emocional

\footnotetext{
14 O relacionamento tumultuado de Dunga com a imprensa brasileira durante a Copa explicitou-se em vários episódios. $O$ que teve maior repercussão ocorreu no dia 20 de junho de 2010, após a vitória de $3 \times 1$ sobre a Seleção da Costa do Marfim, quando o treinador impediu que a jornalista Fátima Bernardes e a equipe de reportagem da Rede Globo realizassem uma entrevista com um grupo de jogadores, em estúdio especial da emissora.
} 
dele e dos jogadores, chegando ou não a prejudicar o desempenho da equipe, são questões que, para serem mais bem respondidas, demandam outros estudos que se debrucem sobre esse assunto, prioritariamente.

Por fim, cabe destacar que, apesar de este trabalho ater-se ao campo da produção dos discursos e de seus efeitos de verdade, não significa que se menospreze a importância de estudos sobre a recepção ${ }^{15}$ desses discursos, ou mesmo que se acredite que eles serão assimilados de forma passiva pelos sujeitos. Os modos de funcionamento nessa instância são outros, pois estão estruturados segundo as condições de interpretação daqueles que ocupam o lugar da recepção. Esses podem se tornar tanto o alvo imaginado, suscetível de perceber os efeitos supostos pela produção, quanto o público que consome esses mesmos discursos, porém produzindo tantos outros efeitos que não 0 pretendido pela produção (CHARAUDEAU, 2006). Dessa forma, o campo da recepção, de como e de quanto esses discursos são recebidos, assimilados, (re)significados ou mesmo utilizados pelos sujeitos, é assunto para outros estudos, feitos a partir de outras metodologias. Por enquanto, o plano da produção satisfez as curiosidades e os objetivos colocados para este estudo. Se o que dizem não pode ser entendido como verdade, tampouco pode ser classificado como mentira. Não se trata, portanto, de um jogo que desvela verdades e mentiras. Aquilo que escolhemos ler e ver certamente diz um pouco daquilo que somos, seja uma novela, uma revista de fofocas ou o futebol nosso de cada dia.

\section{Referências}

ALVITO, M. A parte que te cabe neste latifúndio: o futebol brasileiro e a globalização. Revista Análise Social, Lisboa, v. 41, n. 179, p. 451-474, 2006.

BEM, Amigos: programa esportivo com a presença do técnico da seleção brasileira de

\footnotetext{
15 Assim, apenas a titulo introdutório, trazem-se aqui as contribuições sobre os modos de endereçamento no cinema feitas por Elizabeth Ellsworth (2001), como um estudo pela perspectiva da recepção. $A$ autora destaca que a maior parte das teorias atuais compartilha da premissa de que "todos os modos de endereçamento 'erram' seus públicos de uma forma ou de outra." (p. 42). Mas, a seguir, a própria autora observa que é justamente isso que "torna possivel ver o endereçamento de um texto como um evento poderoso, mas paradoxal, cujo poder advém precisamente da diferença entre endereçamento e resposta." (p. 42).
}

futebol Dunga. [S.I.]: SPORTV, 12 fev. 2007. 1 videocassete, VHS, color.

\section{CHARAUDEAU, P. Discurso das mídias. São} Paulo: Contexto, 2006.

COPA do mundo de futebol: transmissão do jogo Brasil x França. Alemanha: Globo, 1 jul. 2006. 1 videocassete, VHS, color.

CORREIO DO POVO. Porto Alegre: Record, 02 jul. 2006.

ECO, U. Apocalípticos e integrados. São Paulo: Perspectiva, 1979.

ELLSWORTH, E. Modo de endereçamento: uma coisa de cinema: uma coisa de educação também. In: SILVA, T. T. da (Org.). Nunca fomos humanos: nos rastros do sujeito. Belo Horizonte: Autêntica, 2001. p. 8-76.

ESPORTE espetacular: entrevista com o extécnico da seleção brasileira Carlos Alberto Parreira. [S.I.]: Globo, 13 jul. 2008. 1 videocassete, $\mathrm{VHS}$, color.

FOLHA DE SÃO PAULO. São Paulo: Grupo Folha, 22 jun. 2006.

FOLHA DE SÃO PAULO. São Paulo: Grupo Folha, 02 jul. 2006.

FOLHA DE SÃO PAULO. São Paulo: Grupo Folha, 17 jun. 2007.

FOLHA DE SÃO PAULO. São Paulo: Grupo Folha, 24 ago. 2007.

FOUCAULT, M. A Arqueologia do saber. 4. ed. Rio de Janeiro: Forense Universitária, 1995.

FOUCAULT, M. A ordem do discurso: aula inaugural no Collège de France, pronunciada em 2 de dezembro de 1970. Campinas, SP: Loyola, 1998.

FREITAS, G. S.; RIGO, L. C. Discursos de uma derrota: um estudo da produção discursiva sobre a eliminação da seleção brasileira na Copa do Mundo de 2006. Revista Brasileira de Ciências do Esporte, Campinas, v. 30, n. 3, p. 111-125, maio 2009.

FREITAS, G. S.; RIGO, L. C.; PARDO, E. R. A seleção brasileira de futebol na Copa América de 2007: uma demanda discursiva inacabada.

Revista da Educação Física/UEM, Maringá, v. 20, n. 4, p. 543-554, out./dez. 2009.

\section{GLOBOESPORTE. Dunga é o novo técnico da seleção. Disponível em: $<$ http://globoesporte.globo.com/ESP/Noticia/Arqui}


vo/0,AA1240629-4482,00.html >. Acesso em: 24 jul. 2006a.

GLOBOESPORTE. Dunga: uma história de perseverança. Disponível em:

$<$ http://globoesporte.globo.com/ESP/Noticia/Arqui vo/0, AA1240678-4482,00.html>. Acesso em: 24 jul. $2006 \mathrm{~b}$.

GLOBOESPORTE. Jorginho aprova: Dunga é um líder nato. Disponível em: $<$ http://globoesporte.globo.com/ESP/Noticia/Arqui vo/0, AA1240681-4482,00.html>. Acesso em: 24 jul. 2006c.

GLOBOESPORTE. Jogadores tiveram espírito de seleção. Disponível em:

$<$ http://globoesporte.globo.com/ESP/Noticia/Arqui vo/0,AA1249855-4482,00.html>. Acesso em: 16 ago. 2006d.

GLOBOESPORTE. Retrospectiva: a nova era Dunga na seleção. Disponível em: $<$ http://globoesporte.globo.com/ESP/Noticia/Arqui vo/0, AA1401199-4274,00.html>. Acesso em: 28 dez. 2006e.

GREGOLIN, M. R. Análise do discurso e mídia. Revista Comunicação, Mídia e Consumo, Porto Alegre, v. 4, n. 11, p. 11-15, nov. 2007.

GREGOLIN, M. R. O acontecimento discursivo na mídia: metáfora de uma breve história do tempo. In: GREGOLIN, M. do R. Discurso e Mídia: a cultura do espetáculo. São Carlos: Claraluz, 2003. (Coleção Olhares Oblíquos).

GUEDES, S. L. O Brasil no campo de futebol: estudos antropológicos sobre os significados do futebol brasileiro. Rio de Janeiro: EDUFF, 1998.

HELAL, R. As idealizações de sucesso no imaginário do futebol brasileiro: um estudo de caso. In: HELAL, R.; LOVISOLO; H.; SOARES, A. J. A invenção do país do futebol: mídia, raça e idolatria. Rio de Janeiro: Mauad, 2001. p. 135148.

LACLAU, E. Significantes flotantes y heterogeneidad social. In: LACLAU, E. La razón populista. Buenos Aires: Fondo de Cultura Económica, 2005.

LACLAU, E. Universalismo, particularismo y la cuestión de la idendidad. In: LACLAU, E.

Emancipación y diferencia. Buenos Aires: Ariel, 1996.

MACNEILL, M. Estudos de mídia do esporte e a (re)produção de identidades. Revista Brasileira de Ciências do Esporte, Campinas, v. 28, n. 1, p. 9-38, set. 2006.
MAIRESSE, D. Cartografia: do método à arte de fazer pesquisa. In: FONSECA, T. M. G. F.; KIRST, P. G. (Orgs). Cartografias e devires: a construção do presente. Porto Alegre: Ed. UFRGS, 2003. p. 259-271.

O SUL. Porto Alegre: Rede Pampa, 03 jul. 2006.

REVISTA PLACAR. São Paulo: Abril, n. 1296, jul. 2006.

RIGO, L. C. Memórias de um futebol de fronteiras. Pelotas: Ed. Universitária UFPel, 2004.

ROLNIK, S. Cartografia sentimental:

transformações contemporâneas do desejo. Porto Alegre: Sulina: Ed. UFRGS, 2006.

SILVA, T. T. A produção social da identidade e da diferença. In: SILVA, T. T. (Org.). Identidade e diferença: a perspectiva dos estudos culturais. Petrópolis: Vozes, 2000.

\section{TERRA. Presidente da CBF pede seleção} unida. Disponível em:

$<$ http://esportes.terra.com.br/interna/0, Ol1157300 -El1958,00.html>. Acesso em: 25 set. 2006.

TERRA. Dunga: Tem que ser primeiro na Olimpíada. Disponível em:

$<$ http://esportes.terra.com.br/pequim2008/interna/ $0,0 \mathrm{Ol} 3027221-\mathrm{El} 10378,00>$. Acesso em: 24 jul. 2008.

WAGG, S. Anjos de todos nós?: os treinadores de futebol, a globalização e as políticas de celebridade. Revista Análise Social, Lisboa, v. 41, n. 179, p. 347-369, 2006.

ZERO HORA. Porto Alegre: RBS, 03 jul. 2006.

ZERO HORA. Porto Alegre: RBS, 17 jul. 2007a.

ZERO HORA. Porto Alegre: RBS, 14 out. 2007b.

ZERO HORA. Porto Alegre: RBS, 20 ago. 2008a.

ZERO HORA. Porto Alegre: RBS, 07 set. 2008b.

ZERO HORA. Porto Alegre: RBS, 29 out. 2008c.

ZERO HORA. Porto Alegre: RBS, 30 out. 2008d. 
Endereço:

Gustavo da Silva Freitas

Rua Agenor Oliveira Costa, 382 Bairro Cassino

Rio Grande RS Brasil

96205-280

Telefone: (53) 3236-4408 / Cel.: (53) 9125-4441

e-mail: gsf78_ef@hotmail.com

Recebido em: 20 de abril de 2010.

Aceito em: 20 de setembro de 2011.

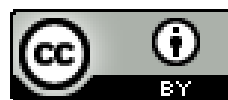

Motriz. Revista de Educação Física. UNESP, Rio Claro,

SP, Brasil - elSSN: 1980-6574 - está licenciada sob

Creative Commons - Atribuição 3.0 